\title{
A Practical Approach To Estimating The Cost Of Equity For South African Firms Undertaking Cross-Border Investments
}

\author{
Vusani Moyo, University of Venda, South Africa
}

\begin{abstract}
Corporate finance literature has developed a number of models for use in estimating the cost equity in for crossborder investments. Most of the models, if not all, are specifically developed for use by US firms investing in emerging markets. The widely used models are the home country CAPM, the local CAPM, the country-risk adjusted CAPM or the Lessard model, the Godfrey-Espinosa model, the Goldman Sachs model, the Gamma model and the SalomonSmithBarney model. Using a hypothetical case study of FirstRand Limited's proposed investments in Ireland and Turkey, this study tests for the suitability of the reverse-engineered versions of these models in estimating the cost of equity for a South African firm planning to invest in both Ireland (developed country) and Turkey (emerging country). The results of the study indicate that the Godfrey-Espinosa the Goldman-Sachs models are equivalent. The Lassard model is equivalent to the Gamma or Damodaran mode, and both models yielded estimates closer to the SalomonSmithBarney model. All the models' estimates for the Turkish investment are consistent with the credit ratings of both Turkey and South Africa. The cost equity estimates show that FirstRand Limited investors will demand an additional risk premium for investments in Turkey. The cost of equity estimates for the Irish investment are mixed, inconsistent with the Ireland's credit rating and had a higher standard deviation than the estimates for the Turkish investment. The Irish estimates seem to be largely affected by the country's high country and banking industry betas. The reverse-engineered versions of these models are suitable for use by firms in emerging countries.
\end{abstract}

Keywords: Local CAPM; Country-Risk Adjusted CAPM; Cost of Equity

\section{INTRODUCTION}

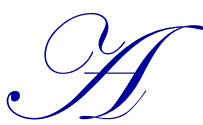

number of corporate finance surveys confirm that the William Sharpe (1962) and John Lintner's (1965) capital asset pricing model (CAPM) is the most popular asset pricing model that analysts, valuation experts, investors, chief financial officers and finance academics use to estimate the cost of equity. For example, a survey by Bruner, Eads, Harris and Higgins (1998) found that 85\% of the best managed United States of America companies use the CAPM in estimating the cost of equity. A CFO survey conducted by Graham and Harvey (2001, p. 210) revealed that $73.5 \%$ of the surveyed CFOs use the CAPM in calculating the cost of equity. Welch (2008) found that 75\% of finance professors recommend the use of the William Sharpe (1962) and John Lintner (1965) CAPM in calculating the cost of equity. Lastly, the Bancel and Mittoo (2014) survey of 365 European finance experts revealed that $80 \%$ of them use the CAPM to estimate the cost of equity.

In the simplest terms, the CAPM states that the investors' required rate of return from a particular share is equal to the risk-free rate plus the share's total risk premium which is defined as the market risk premium multiplied by the share's exposure to the market Sharpe (1962) and Lintner (1965). The investors' required rate of return defines the firm's cost of equity. In a particular market, the proxy for the risk-free rate is normally the yield of a 10-year government bond. The market risk premium is calculated as the overall market return less the risk-free rate. The overall market return is return of the All-Share local Stock Market Index. The share's exposure to the local market is simply its systematic risk scaled up by the market risk. Systematic risk is the product of the correlation coefficient between the share and market returns and the share's risk. Essentially in a country situation, the share's total risk premium is the local price of risk for the share. It compensates the investor for the taking the risk to invest in the share instead of investing in the government bonds which are considered to be risk-free. 
The CAPM works very well for a specific country as there is no ambiguity in terms of all the model's inputs. Now consider a situation where a South African firm like FirstRand Limited for example, is considering expansion into Ireland and Turkey. As of the $15^{\text {th }}$ December 2015, the risk-free rates for South Africa, Ireland and Turkey were $9.50 \%, 1.16 \%$ and $9.85 \%$ respectively. On the same date, their market risk premiums were $8.66 \%, 8.21 \%$ and $9.11 \%$ respectively. The Moody's credit ratings for the countries were respectively Baa2, Baa1 and Baa3. The heterogeneity in risk-free rates, market risk premiums and credit ratings are all due to differences in country risks. Country risk is made up of political, economic and financial risks and thus these three risks differ across the three countries. The country credit ratings mean that country risks decrease from Turkey to Ireland.

The question is: Can FirstRand Limited use the CAPM to estimate the cost of equity for the Irish and Turkish investment projects? The answer is YES, provided the CAPM is correctly modified to also price-in the host country's risk premium. The dilemma that is faced by finance researchers and financial managers of firms involved in crossborder investments is how to modify the basic CAPM so that it also prices-in the additional host country risk premium. In an attempt to solve this dilemma, a number of leading corporate finance researchers which include Estrada (2007, p. 72), Sabal (2004, p. 156), Von Jenner (2008, p. 21), Pereiro (2010, p. 115), Lessard (1996), Mariscal and Hargis (1999) and Damodaran (2002) have developed a number of modified CAPM that can be used by US firms to estimate the cost of equity in cross-border investments. The seven leading models are the home country CAPM, the local CAPM, the country-risk adjusted CAPM or the Lessard model, the Godfrey-Espinosa model, the Goldman Sachs model, the Gamma model and the SalomonSmithBarney model. As these models are specifically developed for US firms investing in emerging markets, can they be reverse-engineered and be used by emerging market firms to estimate to estimate the cost of equity in developed markets and in other emerging market countries?

Using a hypothetical case study of FirstRand Limited's proposed investments in Ireland and Turkey, this study tests for the suitability of these seven models in estimating the cost of equity for a South African firms planning to invest overseas. The results of the study indicate that the Godfrey-Espinosa the Goldman-Sachs models are equivalent. The Lassard model is equivalent to the Gamma or Damodaran mode, and both models yielded estimates closer to the SalomonSmithBarney model. All the models' estimates for the Turkish investment are consistent with the credit ratings of both Turkey and South Africa. The cost equity estimates show that FirstRand Limited investors will demand an additional risk premium for investments in Turkey. The cost of equity estimates for the Irish investment are mixed, inconsistent with the Ireland's credit rating and had a higher standard deviation than the estimates for the Turkish investment. The Irish investment's cost of equity estimates of the home country CAPM, the Godfrey-Espinosa and the Goldman-Sachs models are lower than the firm's South African cost of equity. This result is consistent with the credit ratings of the two countries. The other four models however yielded costs of equity that are higher than the firm's South African cost of equity. The rest of the paper is structured as follows. Section 1 presents the seven models used in the case study. The case study and its solution are presented in Section 2. Section 3 concludes the study.

\section{THE CROSS BORDER EQUITY ASSET PRICING MODELS}

The cross-border CAPM is derived from the basic local CAPM which is stated as:

$$
\begin{aligned}
& \text { Stock's expected risk premium }=\text { stock's beta } \times \text { expected market risk premium } \\
& k_{e}-r_{f}=\beta_{i} \times\left(r_{m}-r_{f}\right) \equiv k_{e}-r_{f}=\beta_{i} \times m r p
\end{aligned}
$$

Where: $k_{e}$ denotes the cost of equity or equity holders' expected rate of return, $r_{f}$ denotes the risk free rate, $r_{m}$ denotes the expected market return, $m r p$ represents the (world) market risk premium and $\beta_{i}$ represents the stock's specific risk. To derive the cross-border CAPM, the foreign country specific risk is added to the basic CAPM. According to Estrada (2007, p. 72), the general cross-border CAPM can be expressed as follows:

$$
k_{e}=r_{f}+m r p \times s r+a
$$


Where:

$$
m r p=\left(r_{m}-r_{f}\right)
$$

Where: $k_{e}$ denotes the cost of equity or equity holders' expected rate of return, $r_{f}$ denotes the risk free rate, $m r p$ represents the (world) market risk premium, $s r$ represents the specific risk of an investment opportunity, $a$ is the additional adjustment to cover the foreign country market risk and $r_{m}$ is the (world) market expected rate of return. The practical approach is to use the world market portfolio to measure market risk and hence the share's systematic risk will be measured against the world portfolio. Researchers and practitioners have developed a number of variants of this model in an attempt to address the sovereign and specific risk. The seven leading models which are discussed below differ in the way they define the inputs of the above general model. In all the seven models, the home country is South Africa and the local country is the foreign country.

\section{The Home Country CAPM (HCAPM)}

The home country is South Africa and the local country is the foreign country. The model simply adds local country risk premium to the home discount rate (Sabal, 2004, p.156; Von Jenner, 2008, p. 21):

$$
k_{e x}=r_{f h}+\beta_{i h}\left(r_{m h}-r_{f h}\right)+r_{x} \equiv r_{f h}+\beta_{i h} \times m r p_{h}+r_{x}
$$

Where: $k_{e x}$ denotes the cost of equity or equity holders' expected rate of return in country $x, r_{f h}$ denotes the home risk free rate measured by the yield of a long-term South African government bond, $\beta_{i h}$ is the share beta based on comparable firm in the home country, and $r_{m h}$ is the home country's expected market return, the proxy being either the return from the JSE's All-Share Index or the worldwide stock market index such as the Morgan Stanley Composite Index (MSCI), $r_{x}$ is country $x^{\prime} s$ market risk, whose proxy is the differential yield spread relative to South Africa. All yield spreads derive from the country's' credit rating or simply the spread of long-term T-bond issued by country $x$ in US dollars over the long-term US T-bond. $r_{x}$ captures all the relevant risks of investing in country $x$ : political, economic and financial risks. This model assumes that country risk is an appropriate measure of equity risk and that this risk is the same for all projects. These assumptions are however flawed. Firstly, equity risk in not driven by credit premiums (country ratings) but by general market movements. Secondly, certain sectors which are favoured by emerging markets may carry a lower country risk premium. These flaws render the model less precise in the pricing of equity asset. Thus, the H-CAPM for FirstRand Limited's investments in Turkey and Ireland can be stated as:

$$
\begin{aligned}
& k_{e, x}=r_{f, S A}+\beta_{i, S A}\left(r_{m, S A}-r_{f, S A}\right)+r_{\text {Turkey }} \equiv r_{f, S A}+\beta_{i, S A} \times m r p_{S A}+r_{\text {Turkey }} \\
& k_{e, \text { Ireland }}=r_{f, S A}+\beta_{i, S A}\left(r_{m, S A}-r_{f, S A}\right)+r_{\text {Ireland }} \equiv r_{f, S A}+\beta_{i, S A} \times m r p_{S A}+r_{\text {Ireland }}
\end{aligned}
$$

\section{Local CAPM (L-CAPM)}

There are three versions of the local CAPM. The first version, which uses the global risk-free rate, and the local riskfree rate, country risk premium, beta and market risk premium was formulated by Pereiro (2001, p. 340) and Pereiro (2006, p. 169). This model is expressed as:

$$
k_{e x}=r_{f G}+r_{x}+\beta_{l x} \times\left(r_{m x}-r_{f x}\right) \equiv r_{f h}+r_{x}+\beta_{l l} \times m r p_{x}
$$

Where: $r_{f G}$ is the global risk-free rate, $r_{x}$ is the country risk premium, $\beta_{l x}$ the beta of a comparable local company local company or industry which is calculated against the against local market index. For example, in Turkey, the share returns are measured against the returns of the BORSA Istanbul's -All Share Index, that is:

$$
\beta_{l, \text { Turkey }}=\frac{\sigma_{i, \text { Turkey }}}{\sigma_{m, \text { Turkey }}}
$$


The Pereiro (2001, p. 340) and Pereiro (2006, p. 169) local CAPM for Turkey can therefore also be expressed as;

$$
k_{e x}=r_{f, G}+r_{\text {Turkey }}+\frac{\sigma_{i, \text { Turkey }}}{\sigma_{m, \text { Turkey }}} \times\left(r_{m, \text { Turkey }}-r_{f, \text { Turkey }}\right)
$$

This can also be expressed as:

$$
k_{\text {ex }}=r_{f, G}+r_{\text {Turkey }}+\frac{\sigma_{i, \text { Turkey }}}{\sigma_{m, \text { Turkey }}} \times m r p_{\text {Turkey }}
$$

There are however two problems with this version of the local CAPM. The first problem is the mixing of the local country inputs with the global risk-free rate, $r_{f G}$. How does this localise the model? The second problem with this version of the local CAPM is that it double counts the country risk premium by using $r_{x}$ and $r_{m x}$ is the same equation. The main difficulties of using this model are lack of credible data to calculate the inputs to the model and a suitable proxy for the global risk-free rate. For example: genuine risk-free rates may not exist in some countries; available data may be limited making the calculation of accurate values of beta and market returns impossible.

Pereiro (2010, p. 115) modified the Pereiro (2001, p. 340) and Pereiro (2006, p. 169) local CAPM by replacing the global risk-free rate, $r_{f G}$, with the home country risk-free rate, $r_{f h}$. This second version of the local CAPM is expressed as follows:

$$
k_{e x}=r_{f h}+r_{x}+\beta_{l x} \times\left(r_{m x}-r_{f x}\right) \equiv r_{f h}+r_{x}+\beta_{l l} \times m r p_{x}
$$

Where: $r_{x}$ is the country risk premium, $\beta_{l x}$ the beta of a comparable local company local company or industry which is calculated against the against local market index. For example, in Turkey, the share returns are measured against the returns of the BORSA Istanbul's -All Share Index, that is:

$$
\beta_{l, \text { Turkey }}=\frac{\sigma_{i, \text { Turkey }}}{\sigma_{m, \text { Turkey }}}
$$

The Pereiro (2010:115) local CAPM for Turkey can therefore also be expressed as;

$$
k_{\text {ex }}=r_{f, \text { South Africa }}+r_{\text {Turkey }}+\beta_{l, \text { Turkey }} \times\left(r_{m, \text { Turkey }}-r_{f, \text { Turkey }}\right)
$$

This can also be expressed as:

$$
k_{e x}=r_{f, \text { South } A \text { frica }}+r_{\text {Turkey }}+\beta_{l, \text { Turkey }} \times m r p_{\text {Turkey }}
$$

Just like the first version of the local CAPM, this modified version of the local CAPM still suffers from the problem of double-counting the country risk premium as it also uses both $r_{x}$ and $r_{m x}$ in the same equation. Again, this model is however justified provided there is credible data available.

The third version of the local CAPM was formulated by Sabal (2004, p. 158) and Von Jenner (2008, p. 22). This version of the local CAPM uses the host country's local risk-free rate, beta and market return to estimate the cost of equity. As local data is used, there is no need to adjust for the country risk premium as this is assumed to be included in the model's inputs. The Sabal (2004, p. 158) and Von Jenner (2008, p. 22) local CAPM is expressed as follows:

$$
k_{e x}=r_{f x}+\beta_{i x}\left(r_{m x}-r_{f x}\right) \equiv r_{f x}+\beta_{i x} \times m r p_{x}
$$

Where: is the risk-free rate of country $x ; \beta_{i x}$ is the beta of an investment $i$ with respect to the market portfolio in country $x ; r_{m x}$ is the expected return of the market portfolio in country $x$ and $m r p$ is the market risk premium for country $x$. Thus, for an investment in Turkey, the local CAPM would be: 


$$
k_{\text {ex }}=r_{f, \text { Turkey }}+\beta_{i, \text { Turkey }}\left(r_{m, \text { Turkey }}-r_{f, \text { Turkey }}\right)
$$

This can also be expressed as:

$$
k_{\text {ex }}=r_{f, \text { Turkey }}+\beta_{i, \text { Turkey }} \times m r p_{\text {Turkey }}
$$

This is truly a local CAPM as it uses $100 \%$ local input data. The model is very easy to apply provided there is sufficient local data. The question that arises with the three versions of the local CAPM is whether the return obtained will be enough to compensate the overseas investors. The home country investors will need to compare the result with their expected return in their home mark.et to assess if it's profitable to proceed with the foreign project. This study only used the Pereiro (2010, p. 115), and the Sabal (2004, p. 158) and Von Jenner (2008, p. 22) version of the local CAPMs.

\section{The Country Risk Adjusted CAPM (CRA-CAPM) or the Lessard (1996) Model}

According to Lessard (1996, p. 60) the beta of an offshore project is the product of the beta of comparable home country project and the beta of the local country. This product is called specific risk as it relates to the risk of a specific project in a specific country. Estrada (2007, p. 73) expresses the Lessard (1996) model as:

$$
k_{e x}=r_{f, S A}+\beta_{x} \times \beta_{p} \times\left(r_{m, w}-r_{f, w}\right)
$$

Where: $\beta_{x, S A}$ is the country beta of the local country and $\beta_{p}$ is the beta of the local industry; it is the project beta and $\left(r_{m, w}-r_{f, w}\right)$ is the world risk premium. The product $\left(\beta_{x} \times \beta_{p}\right)$ is called specific risk as it relates to the risk of a specific project in a specific country. Both Lessard (1996, p. 60) and Estrada (2007, p. 73) argue that there is no need to include the country risk premium in the model as this is fully captured by the country beta, $\beta_{x}$. The Lessard (1996, p. 60) model for the Turkish investment will thus be expressed as:

$$
k_{\text {ex }}=r_{f, S A}+\beta_{\text {Turkey }} \times \beta_{\text {Bank }} \times\left(r_{m, w}-r_{f, w}\right)
$$

Pereiro (2006, p. 169), Pereiro (2010, p. 116) and Von Jenner (2008, p. 21) modified the Lessard (1996) model to include the country risk premium and use relative beta instead of the country beta. The modified Lessard (1996) model is expressed as:

$$
k_{e x}=r_{f, S A}+r_{x}+\beta C_{x, S A} \times \beta_{S A} \times\left(r_{m, S A}-r_{f, S A}\right)
$$

Where: $\beta C_{x, S A}$ is the country beta which is the relative sensitivity of the returns of the local stock market to the South African market's returns. The country beta is calculated as:

$$
\beta C_{x, S A}=\rho_{x, S A} \times \frac{\sigma_{x}}{\sigma_{S A}}
$$

Where: $\rho_{x, S A}$ is the correlation between the local market and the South African market, $\sigma_{x}$ is the equity returns standard deviation of the local country and $\sigma_{S A}$ is the equity returns standard deviation of the South African market. Thus, in this modified model, both: $r_{x}$ and $\beta C_{x, S A}$ account for the country-specific risk. Pereiro (2006, p. 169) contends that this model double-counts risk as it includes both $r_{x}$ and $\beta C_{x, S A}$. This therefore renders the model less precise than the original version of the Lessard (1996) model. For this reason, the study only tested the original version of the Lessard (1996) model.

\section{The Godfrey-Espinosa Model}

According to Godfrey and Epinosa (1996), the only risks that matter in cross-border investment are the political, business and currency risks. Firms involved in cross-border investments can completely eliminate currency risk by using a hard currency like the US dollar, Pound Sterling or the Euro as the base currency for the project. If the US 
dollar is chosen as the base currency for the project, it follows that the CAPM used will also use the US risk-free rate and market risk premium. The political and business risks are incorporated into the CAPM through the use of adjusted beta and the country risk premium. As most global trade is done in US dollars, the US dollar is normally used as the base currency in most cross-border investments. The Godfrey-Espinosa model is therefore expressed as Sabal (2004, p. 160):

$$
k_{e x}=r_{f, U S}+\beta_{a d j} \times\left(r_{m, U S}-r_{f, U S}\right)+c r_{x}
$$

The risk-free rate $\left(r_{f, U S}\right)$ and the market risk premium $\left(\left(r_{m, U S}-r_{f, U S}\right)\right)$ are those of the US market. The credit spread or country risk spread for country $x$ (political and business risks) $\left(c r_{x}\right)$ is the spread of long-term T-bond issued by country $x$ in US dollars over similar long-term US T-Bond). This effectively means that the risk-free rate $\left(r_{f h}\right)$ is adjusted for the country spread $\left(c r_{x}\right)$ :

$$
k_{e x}=\left(r_{f, U S}+c r_{x}\right)+\beta_{a d j} \times\left(r_{m, U S}-r_{f, U S}\right)
$$

According to Godfrey and Epinosa (1996: ) and Sabal (2004:160), the adjusted beta is defined as:

$$
\beta_{a d j}=\frac{\sigma_{x}}{\sigma_{m, U S}}
$$

$\sigma_{x}$ is the standard deviation of returns of similar local market shares and $\sigma_{m, U S}$ is the standard deviation of returns of similar shares in the US market. Thus, the model can also be expressed as:

$$
k_{e x}=\left(r_{f, U S}+c r_{x}\right)+\left(\frac{\sigma_{x}}{\sigma_{m, U S}}\right) \times\left(r_{m, U S}-r_{f, U S}\right)
$$

According to Erb, Harvey, and Viskanda (1995), up to $40 \%$ of the variation in equity volatility can be explained by changes in credit spread whilst $60 \%$ is related to variations in business conditions. Thus to reduce the double-counting of risk, the adjusted beta, $\beta_{a d j}$, is multiplied $60 \%$. This adjustment yields the Godfrey \& Espinosa (1996) model which is stated as (Sabal, 2004, p. 161; Pereiro, 2001, p. 343; Pereiro, 2006, p. 169).

$$
k_{e x}=\left(r_{f, U S}+c r_{x}\right)+0.6 \times \beta_{a d j} \times\left(r_{m, U S}-r_{f, U S}\right)
$$

This model can also be expressed as:

$$
k_{e x}=\left(r_{f, U S}+c r_{x}\right)+\left(0.6 \times \frac{\sigma_{x}}{\sigma_{m, U S}}\right) \times\left(r_{m, U S}-r_{f, U S}\right)
$$

For the ease of comparison with other models, the study modified this model to use South African data. The modified model is:

$$
k_{e x}=\left(r_{f, S A}+c r_{x}\right)+\left(0.6 \times \frac{\sigma_{x}}{\sigma_{m, W}}\right) \times\left(r_{m, W}-r_{f, W}\right)
$$

Estrada (2007, p. 73) presents a modified Godfrey and Espinosa (1996) CAPM where the adjusted beta is calculated against the standard deviations of returns of the world market as opposed to those of the US market. The adjusted beta is calculated as:

$$
\beta_{a d j}=0.6 \times \frac{\sigma_{x}}{\sigma_{W}}
$$


Where: $\sigma_{x}$ and $\sigma_{W}$ are the respectively standard deviations of returns of the emerging country's stock market relative to that of the world market. The basic model therefore reduces to:

$$
k_{e x}=\left(r_{f, U S}+c r_{x}\right)+\left(0.6 \times \frac{\sigma_{x}}{\sigma_{W}}\right) \times\left(r_{m, W}-r_{f, W}\right)
$$

Again the study modified this model to use the South African Risk-free rate. The modified model is:

$$
k_{e x}=\left(r_{f, S A}+c r_{x}\right)+\left(0.6 \times \frac{\sigma_{x}}{\sigma_{W}}\right) \times\left(r_{m, W}-r_{f, W}\right)
$$

The modified version that use South African data are therefore equivalent. The main problem is how do you calculate the spread if country $x$ does not issue long-term US dollar denominated T-bonds? The solution may be to use credit ratings to calculate the spread. The model also ignores the specific nature of the project as it uses average beta instead of a project-specific beta.

\section{The Goldman Sachs (G-S) Model}

Mariscal and Hargis (1999) improved on the Godfrey and Espinosa (1996) by replacing the $60 \%$ fixed adjustment of the project's specific risk by the term one minus the correlation between the local country's stock and bonds markets. This, they claim avoids the problem of double counting. The project's specific risk is therefore calculated as:

$$
\beta_{i}=\left(1-\rho_{s b, x}\right) \times \frac{\sigma_{x}}{\sigma_{S A}}
$$

Where: $\rho_{s b, x}$ is the correlation between the local country's stock and bond markets; $\sigma_{x}$ and $\sigma_{S A}$ are the respectively standard deviations of returns of the local country's stock market relative to that of the South African market. The Goldman Sachs model is therefore an improvement of the Godfrey and Espinosa (1996) and it is stated as:

$$
k_{e x}=r_{f, S A}+r_{x}+\left(r_{m, S A}-r_{f, S A}\right) \times\left\{\left(1-\rho_{s b, x}\right) \times \frac{\sigma_{m \cdot x}}{\sigma_{m, S A}}\right\}
$$

Estrada (2007, p. 73) presents a modified Goldman-Sachs CAPM where the standard deviation of the home country is replaced by the standard deviation of the world market, $\sigma_{m w}$, that is:

$$
k_{e x}=r_{f, S A}+r_{x}+\left(r_{m, W}-r_{f, W}\right) \times\left\{\left(1-\rho_{s b, x}\right) \times \frac{\sigma_{m x}}{\sigma_{m W}}\right\}
$$

The term $\left\{\left(1-\rho_{s b, x}\right) \times \frac{\sigma_{m x}}{\sigma_{m w}}\right\}$ still measures the specific risk of the project. The study used the Estrada (2007) model.

\section{The SalomonSmithBarney Approach}

Zenner and Akaydin (2002) of the consultancy firm SalomonSmithBarney proposed a CAPM that splits local country's political into three elements: access to capital markets, susceptibility of the proposed investment to political risk and importance of the proposed project to the company. These three elements are each measured on a scale of 0 to 10 and thus the maximum score of 30 . Thus the political risk premium is adjusted for by using the following index:

$$
A=\frac{\left(\gamma_{1}+\gamma_{2}+\gamma_{3}\right)}{30} \times r_{x}
$$

Where: each $\gamma$ coefficient is measured on a scale $0-10, \gamma_{1}$ captures the firm's access to capital markets $(0=$ full access, $10=$ no access $), \gamma_{2}$ captures the susceptibility of the investment to political risk $(0=$ no susceptibility and $10=$ full 
susceptibility) $\gamma_{3}$ captures the financial importance of the project to the firm $(0=$ not very important, involves a small portion of capital and $10=$ very important, involves a significant amount of the firm's capital). The sum of the coefficients is $30\left(\gamma_{1}+\gamma_{2}+\gamma_{3}=30\right) . r_{x}$ is the yield spread that captures the country's political risk premium. The original SalomonSmithBarney model is stated as (Zenner \& Akaydin, 2002, p. 17; Pereiro, 2006, p. 170):

$$
k_{e x}=r_{f, h}+E M R P \times \beta_{G}+\left(\frac{\gamma_{1}+\gamma_{2}+\gamma_{3}}{30}\right) \times P R P
$$

Where: EMRP is the global equity market risk premium, $\beta_{G}$ is the global CAPM beta for the target company corresponding to the optimal capital structure and the industry of the proposed investment and $P R P$ is unadjusted political risk premium. Estrada (2007, p. 740) presented a modified SalomonSmithBarney model that uses project beta and local market risk premium and risk-free rate:

$$
k_{e x}=r_{f, h}+\beta_{P} \times\left(R_{m, W}-R_{f, W}\right)+\left(\frac{\gamma_{1}+\gamma_{2}+\gamma_{3}}{30}\right) \times r_{x}
$$

This study used the Estrada (2007) modified model.

\section{The Gamma or Damodaran (2002) Model}

This was derived by Damodaran (2002). The Gamma or the Damodaran model uses a gamma factor as a measure of firm-specific exposure to country risk. The Gamma factor has a scale of zero to one and its proxy may be: the revenues derived from the local country or assets held in local country or profits earned in local country relative to those of home country. The model therefore adjusts country risk to firm-level as well. Pereiro (2006, p. 170) and Pereiro (2010, p. 115) expressed the model as follows:

$$
k_{e x}=r_{f, S A}+r_{x} \times \gamma_{i}+\beta_{p} \times\left(r_{m, W}-r_{f, W}\right)
$$

Where: $\gamma_{i}$ is the firm's exposure to country risk, scale ranges from 1 to 0 .

\section{CASE STUDY}

Assume that FirstRand Limited, one of the largest financial services firms in South Africa is planning to expand its operations into Turkey and Ireland. After modelling the project cash flows, the Chief Financial Officer is left with the daunting task of estimating a suitable discount rate to use in the evaluation of the two project. She identified the Türkiye İş Bankası and the Allied Irish Banks plc as suitable Turkish and Irish peers respectively. The banks' information is contained in Table 2.0 below.

Table 2.0 shows the total asset values, numbers of employees and bank betas of the South African FirstRand Limited, the Turkish Türkiye İş Bankası and the Irish Allied Irish Banks plc. The bank betas were obtained from the Financial Times' database.

Table 2.0. Bank Financial Information

\begin{tabular}{l|c|c|c}
\hline & South Africa & Turkey & Ireland \\
\hline Bank & FirstRand Limited & Türkiye İş Bankas1 & Allied Irish Banks plc \\
\hline Total asset value & USD \$89 billion & USD \$71.10 billion & USD \$117.5billion \\
\hline Employees & 38,989 & 24,308 & 11,050 \\
\hline Bank local beta & 0.8355 & 1.28 & 3.62 \\
\hline
\end{tabular}

The CFO has also collected some financial information about the three countries and this is contained in Table 1.0.

Table 1.0 contains an extract of some financial information for South Africa, Turkey and Ireland. The risk-free rates are the yields of the 10-year bonds of the respective countries. These were obtained from the Financial Times' 
database. Except for the correlation between the stock and bonds markets and the Gamma indices, all the other data was obtained from the Damodaran database. The correlation between the stock and bonds markets and the Gamma indices were respectively assumed to be $40 \%$ and $10 \%$ for each market.

Table 1.0. Financial information

\begin{tabular}{|c|c|c|c|}
\hline & South Africa & Turkey & Ireland \\
\hline Risk-free rate & $9.50 \%$ & $9.850 \%$ & $1.16 \%$ \\
\hline Equity risk premium & $8.66 \%$ & $9.11 \%$ & $8.21 \%$ \\
\hline World market risk premium & $9.35 \%$ & $9.35 \%$ & $9.35 \%$ \\
\hline Yield-spread relative to the US & $2.85 \%$ & $3.30 \%$ & $2.40 \%$ \\
\hline Yield relative to South Africa & - & $0.45 \%$ & $-0.45 \%$ \\
\hline Country beta & 1.05 & 1.05 & 1.19 \\
\hline Country bank (Money Centre) beta & 0.84 & 0.84 & 1.72 \\
\hline Stock market volatility & $13.79 \%$ & $25.06 \%$ & $16.07 \%$ \\
\hline World stock market volatility & $16.08 \%$ & $16.08 \%$ & $16.08 \%$ \\
\hline Correlation between stock and bond markets & 0.40 & 0.40 & 0.40 \\
\hline Gamma & - & 1.00 & 1.0 \\
\hline
\end{tabular}

The CFO has also identified the Türkiye İş Bankası and the Allied Irish Banks plc as suitable Turkish and Irish peers respectively. The banks' information is contained in Table 2.0 below.

\section{Solution: The Cost of Equity in Turkey and Ireland}

The models' estimates for the cost of equity are contained in Table 3.0.

Table 3.0 shows the results of the models' estimated cost of equity for FirstRand Limited in South Africa, Turkey and Ireland. The models' input data is contained in Tables 1.0 and 2.0.

Table 3.0. FirstRand Limited's cost of equity in Turkey and Ireland

\begin{tabular}{l|cc}
\hline & Turkey & Ireland \\
\hline FirstRand's cost of equity in South Africa & $16.7354 \%$ & $16.7354 \%$ \\
\hline Home country CAPM model & $17.1854 \%$ & $16.2854 \%$ \\
\hline Local CAPM : Pereiro (2010) model & $21.6108 \%$ & $38.7702 \%$ \\
\hline Local CAPM : Sabal (2004) model & $21.5108 \%$ & $30.8802 \%$ \\
\hline Lassard or country risk CAPM model & $17.7467 \%$ & $28.6376 \%$ \\
\hline Godfrey-Espinosa model & $18.6929 \%$ & $14.6565 \%$ \\
\hline Goldman-Sachs model & $18.6929 \%$ & $14.6565 \%$ \\
\hline SalomonSmithBarney model $1\left(\gamma_{1}, \gamma_{2}, \gamma_{3}=0,0,0\right)$ & $17.3540 \%$ & $17.3540 \%$ \\
\hline SalomonSmithBarney model 1 $\left(\gamma_{1}, \gamma_{2}, \gamma_{3}=10,10,10\right)$ & $17.8040 \%$ & $16.9040 \%$ \\
\hline SalomonSmithBarney model $1\left(\gamma_{1}, \gamma_{2}, \gamma_{3}=5,5,5\right)$ & $17.5790 \%$ & $17.1290 \%$ \\
\hline Damodaran or Gamma model & $17.7467 \%$ & $28.6376 \%$ \\
\hline Standard deviation & $1.34 \%$ & $6.44 \%$ \\
\hline
\end{tabular}

First Rand Limited's current cost of equity in South Africa is $16.7354 \%$. In both countries, the Godfrey-Espinosa and the Goldman-Sachs models yielded similar estimates and this confirms their equivalence. In both countries, the Lassard and Gamma or Damodaran models yielded similar estimates and this confirms their equivalence. For Turkey, the estimates of the SalomonSmithBarney model are closer to those of the Damodaran or Gamma and Lassard models. The two versions of the local CAPM tend to overestimate the cost of equity as they yielded estimates that are higher than those of their peers in both countries. The standard deviation of the models' Turkish estimates is only $1.34 \%$ compared to the $6.44 \%$ for Ireland's estimates. The small standard deviation for the Turkish investment's cost of equity imply that the seven models are almost equivalent. Furthermore, all the Turkish cost of equity estimates are higher than the FirstRand Limited's current cost of equity in South Africa. The Turkish investment's results are in line with the credit ratings of the two countries. As Turkey's credit rating of Baa3 is lower than South Africa' credit rating of Baa2, it is expected that South African investors will demand an additional risk premium when investing in Turkey. 
What went wrong in Ireland? Based on the risk model, the expectation is that First Rand Limited investors will take a discount in their required rate of return from the Irish investment. This is because Ireland is less risky than South Africa as its credit rating of Baal is higher than South Africa's Baa 2 credit rating. This is certainly not the case. It is only the home country CAPM, the Godfrey-Espinosa and the Goldman-Sachs models' estimates that confirm this hypothesis. The other models' estimates are significantly higher than the company's current cost of equity in South Africa and these estimates imply that FirstRand investors will demand an additional risk premium that is higher than that of Turkey when investing in Ireland. How is this possible? Firstly, the home country CAPM, the GodfreyEspinosa and the Goldman-Sachs models' have one common feature: unlike all the other models, they don't use the Irish betas. Secondly, all the other models use Irish betas which are all significantly higher than those of both Turkey and South Africa. For example, FirstRand Limited's beta is only 0.8355 compared to 3.62 for the Allied Irish Bank plc. The Turkish bank, Türkiye İş Bankası has a beta of 1.28 which is closer to that of FirstRand Limited. Thus, for the Irish investment, the difference in the models' results is caused by the high Irish beta values. The high Irish country and banking industry betas reflect the underlying high risk of the Irish banking industry. Given this high risk, South African investors will therefore demand a premium instead of a discount when investing in Irish banks. As the home country CAPM, the Godfrey-Espinosa and the Goldman-Sachs models do not use the host country betas, they fail to price-in industry risk in cases where it is significantly differs from the country risk and hence the three models understate the cost of equity in such cases. The other models' estimates therefore correctly reflect the cost of equity for the Irish investment.

\section{CONCLUSION}

Using a hypothetical case study of FirstRand Limited's proposed investments in Ireland and Turkey, this study tests for the suitability of seven widely used variants of the CAPMs in estimating the cost of equity for South African firms planning to invest in these two countries. The results of the study indicate that the Godfrey-Espinosa the GoldmanSachs models are equivalent. The Lassard model is equivalent to the Gamma or Damodaran mode, and both models yielded estimates closer to the SalomonSmithBarney model. All the models' estimates for the Turkish investment are consistent with the credit ratings of both Turkey and South Africa. The cost equity estimates show that FirstRand Limited investors will demand an additional risk premium for investments in Turkey. The cost of equity estimates for the Irish investment are however mixed, inconsistent with the Ireland's credit rating. Furthermore, the estimates had a higher standard deviation than the estimates for the Turkish investment. The Irish investment's cost of equity estimates of the home country CAPM, the Godfrey-Espinosa and the Goldman-Sachs models are lower than the firm's South African cost of equity. This result is consistent with the credit ratings of the two countries. The other four models however yielded costs of equity that are higher than the firm's South African cost of equity. The main difference between the Godfrey-Espinosa and the Goldman-Sachs models and the other four models is that the latter models use Irish country and industry betas which are higher than those of both Turkey and South Africa. The Irish results imply that the earlier models do not correctly price-in industry risk in cases where it is higher than the home country. Finally, the relationship between industry betas and the total country risk needs further investigation in order to ascertain if the country spread truly prices-in high industry betas.

\section{AUTHOR BIOGRAPHY}

Vusani Moyo (PhD, MBA, MSc, BA (Hons), ACA (ICAEW), FCMA (CIMA), FCCA (ACCA) is an Associate Professor at the University of Venda, South Africa. He obtained his PhD (Financial Management Sciences), an MSc (Finance) and MBA (Finance) from the University of Pretoria, University of Leicester School of Management and the University of Manchester Business School respectively. His current research interests are capital structure of African financial and non-financial firms, cash flow sensitivity of cash, investment cash flow sensitivity of cash, cost of capital, firm valuation and dividend policy.

\section{REFERENCES}

Bancel, F. \& Mittoo, U. R. (2014). The gap between theory and practice of corporate valuation: Survey of European experts. Journal of Applied Corporate Finance, 26(4), 106-117.

Bruner, R. K., Eads, R., Harris, R. \& Higgins, R. (1998). Best practices in estimating the cost of capital: Survey and synthesis. Financial Practice and Education, 8(1), 13-28.

Damodaran, A. (2002). Investment valuation. John Wiley \& Sons, New York. 
Erb, C., Harvey, C. H. \& Viskanda, T. (1995). Expected returns and volatility in 135 countries. Journal of Portfolio Management, $22(4), 46-58$

Estrada, J. (2007). Discount rates in emerging markets: Four models and an application. Journal of Applied Corporate Finance, 19(2), 72-77.

Godfrey, S. \& Espinosa, R. (1996). A practical approach to calculating costs of equity for investments in emerging markets. Journal of Applied Corporate Finance, 9(3), 80-90.

Graham, J. R. \& Harvey, C. R. (2001). The theory and practice of corporate finance: Evidence from the field. Journal of Financial Economics, 60(2-3), 187-243.

Lessard, D. (1996). Incorporating country risk in the valuation of offshore projects. Journal of Applied Corporate Finance, 9(3), 52-63.

Lintner, J. (1965). The valuation of risk assets and the selection of risky investments in stock portfolio and capital budgets. Review of Economics and Statistics, 47(1), 13-37.

Mariscal, J. \& Hargis, K. (1999). A long-term perspective on short-term risk-long-term discount rates for emerging markets. Global Markets Report, Goldman Sachs, October 26, 1999.

Pereiro, L. E. (2010). The beta dilemma in emerging markets. Journal of Applied Corporate Finance, 22(4), 110-122.

Pereiro, L. E. 2006. The practice of investment valuation in emerging markets: Evidence from Argentina. Journal of Multinational Financial Management, 16(2), 160-183.

Pereiro, L. E. (2001). The valuation of closely-held companies in Latin America. Emerging Markets Review, 2(1), 330-370.

Sabal, J. (2004). The discount rate in emerging markets: A guide. Journal of Applied Corporate Finance, 16(2-3), 157-166.

Sharpe, W. F. (1962). Capital asset prices: a theory of market equilibrium under conditions of risk. The Journal of Finance, $19(3), 425-442$.

Welch, I. (2008). The consensus estimate for the equity premium by academic financial economists in December 2007. Unpublished Working Paper, Brown University. [Online] Available from: http://papers.ssrn.com/sol3/papers.cfm?abstract_id=1084918. [Downloaded: 2014-11-12].

Von Jenner, M. H. (2008). Calculating the cost of equity in emerging markets. The FINSIA Journal of Applied Finance, $4,21-25$. Zenner, M. \& Akaydin, E. (2002). A practical approach to the international valuation \& capital allocation puzzle. Global Corporate Finance Papers, SalomonSmithBarney, 3-31. 
NOTES 